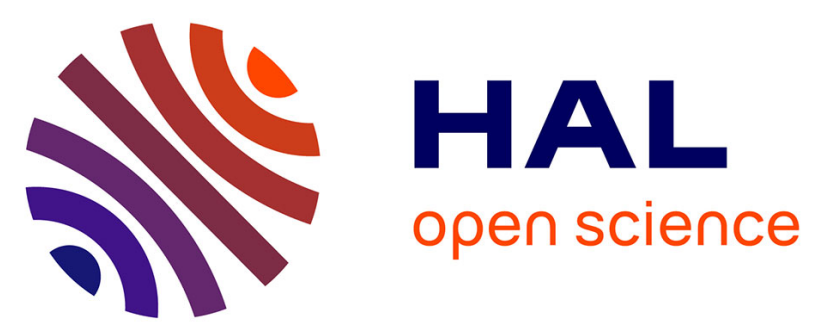

\title{
Video games in adolescence and emotional functioning: Emotion regulation, emotion intensity, emotion expression, and alexithymia
}

\author{
Sophie Gaetan, Vincent Bréjard, Agnès Bonnet
}

\section{- To cite this version:}

Sophie Gaetan, Vincent Bréjard, Agnès Bonnet. Video games in adolescence and emotional functioning: Emotion regulation, emotion intensity, emotion expression, and alexithymia. Computers in Human Behavior, 2016, 61, pp.344-349. 10.1016/j.chb.2016.03.027 . hal-01314720

HAL Id: hal-01314720

https://hal-amu.archives-ouvertes.fr/hal-01314720

Submitted on 13 Oct 2016

HAL is a multi-disciplinary open access archive for the deposit and dissemination of scientific research documents, whether they are published or not. The documents may come from teaching and research institutions in France or abroad, or from public or private research centers.
L'archive ouverte pluridisciplinaire HAL, est destinée au dépôt et à la diffusion de documents scientifiques de niveau recherche, publiés ou non, émanant des établissements d'enseignement et de recherche français ou étrangers, des laboratoires publics ou privés. 


\title{
Video games in adolescence and emotional functioning: Emotion regulation, emotion intensity, emotion expression, and alexithymia
}

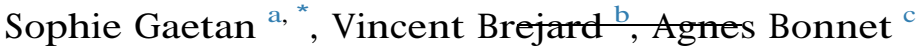 \\ a Aix-Marseille Universite, Institut des Sciences du Mouvement, CNRS-UMR 7287, 13288 Marseille Cedex 09, France \\ b Aix-Marseille Universite, Laboratoire de Psychopathologie Clinique: Langage et Subjectivite, EA 3278, 13331 Marseille, France \\ ${ }^{c}$ Universite Lyon 2 Lumiere, Laboratoire Sante, Individu et Societe, EAM 4128, 69002 Lyon, France
}

Keywords:

Video game

Adolescent

Emotional functioning

Regular gamer

\section{a b s t r a c t}

Video-game users represent $40 \%$ of the French population and adolescents are the primary users. Yet excessive playing of video games has become a problem in modern society and is manifesting itself in treatment centers for adolescents. Before attempting to gain insight into this problematic use, we must understand video gaming itself and its implications for the gamer. The aim of this research is to propose an understanding of video-game playing based on some dimensions of emotional functioning such as emotion regulation, emotion intensity, emotion expression, and alexithymia. A total of 159 adolescents took part in the study. Regular gamers regulated their emotions more than irregular gamers did. They also felt their emotions more intensely. But regular gamers expressed their emotions less than irregular gamers did. Finally, the regular gamers' alexithymia level was higher than the irregular gamers' level. Especially, they had more difficulty being emotionally reactive. The avatar's evolution in the virtual environment may help mediate adolescents' problematic emotional experiences to give them meaning and enable their appropriation. As such, video games may act as a medium for projecting and experiencing one's emotional life by staging the emotional self, thereby explaining the engagement of adolescents in video gaming.

\section{Introduction}

Video games represent the number one cultural industry in the world in terms of sales and the craze they have aroused, especially in France where nearly $40 \%$ of the population reports being users/ gamers (Interactive Software Federation of Europe (ISFE), 2010). Today, video games have become a widespread leisure activity for all generations, although male adolescents remain the primary users of new technologies, especially video games (Bioulac \& Michel, 2012; Fortin, Mora, \& Tremel, 2005; Gentile, 2009; Young, 2009). Indeed, about $90 \%$ of adolescents see themselves as video gamers (French Videogame Agency, 2010) and they play more intensively and more regularly than older gamers (ISFE, 2010). However, excessive playing of video games has become a problem and is manifesting itself in treatment centers for adolescents. Currently, there is no consensus concerning the definition of videogame addiction (Blaszczynski, 2008; Ko, Yen, Chen, Yeh, \& Yen,

* Corresponding author

E-mail address: sogaetan@gmail.com (S. Gaetan).
2009; Turner, 2008; Wood, 2008), although adolescents are known to be a "risky population" when it comes to addiction (Griffiths, 2010; Griffiths, Davies, \& Chappell, 2004; Yen, Yen, Chen, Chen, \& Ko, 2007). They are vulnerable to problems of addiction especially to video-game playing since it is an object in which they are highly prone to engage. To gain insight into this excessive use, it is necessary, upstream, to understand the practice of regular video gaming.

\section{Theoretical review}

Video gaming is based on the interaction between the player and his/her avatar, and the virtual world, two essential components common to all video games. Indeed, the avatar is the virtual character embodied by the player; it allows him/her to interact with and upon a virtual world. The avatar can be seen not only as a visual depiction of the gamer (more or less imposed) but also as an abstract instance (such as in strategy games). The virtual world constituted by a video game is a space for experimentation (Janssen \& Tortolano, 2010) in which the player can engage, a virtual environment in which the player can evolve. The virtual environment 
does not replace the real one, but gives it meaning and mediates the player's relationship to the world (Weissberg, 2006). The avatar is a virtual self (Bessiere, Seay, \& Kisler, 2007; Gaetan, Bonnet, \& Pedinielli, 2012; Seung-A, 2011; Wan \& Chiou, 2006), and the avatar's "virtual body" embodies the gamer and integrates him/her into the virtual environment (Craipeau \& Seys, 2005), perceived by gamers as more logical and more consistent than reality (Fortin et al., 2005; Turkle, 1995).

Adolescents are known to be subject to "over-arousal" of their body and emotions (Michel, 2001), a state which is hard for them to understand and control, but which they must appropriate and incorporate into their identity constructions (Michel, 2001). The body is a space for experimentation that occupies a central place in the emergence and expression of emotions (Lupton, 1998; Lyon \& Bardalet, 1994). Emotional experiences form one of the bases of the self (Lupton, 1998) and enable subjects to enter into relationships with the surrounding world (Lyon \& Bardalet, 1994). Emotional experiences are characterized and structured by a dynamic entity, the "emotional self" (Lupton, 1998), which itself is structured by the meanings given to bodily experiences. It allows the subject to identify and express emotions. Emotional experience results from the emotional processing (Greenberg, 2004) that interconnects three components: emotional valence, which corresponds to the positive or negative quality the subject attributes to the emotion (Gross \& John, 2003); emotion activation or emotion intensity, which corresponds to the force with which the emotion is felt by the subject (Larsen \& Diener, 1987); and emotion expression, which puts the emotion at the center of the interactional dynamics (Kring, Smith, \& Neale, 1994). Several works showed that media may ostensibly be used as an external means of mood regulation (Greenwood \& Christopher, 2009). Difficulty feeling control of one's emotion or behavior was the primary predictor of using media in negative moods (Greenwood, 2008; Greenwood \& Christopher, 2009). Furthermore, problematic emotional regulation, including difficulty to identify and express emotions, is linked to conduct problems in children and adolescents (Mullin \& Hinshaw, 2007; Southam-Gerow \& Kendall, 2002) and may be considered as a vulnerability factor for delinquent behavior and substance abuse in adolescence (Dorard, Berthoz, Phan, Corcos, \& Bungener, 2008; Zimmermann, 2006).

The aim of this research is to propose a description of videogame playing, based on some dimensions of emotional functioning such as emotion regulation, emotion intensity, emotion expression, and alexithymia. In this prospective study, we do not distinguish the different types of video game and we consider that an avatar is present in every video game (from visual depiction to abstract instance). We believe that the virtual world of video game offers the player a context in which it is possible for him to react emotionally. The avatar's evolution in the virtual environment acts as a mediator of emotional experiences that would be problematic (in their identification, regulation and expression) in the everyday environment. The perceived greater consistency and comprehensibility of this virtual environment permits another kind of emotional processing. Identification of emotions induced by the virtual environment may be less problematic in a video-game context. Adolescents who are unable to identify and describe their emotions may therefore be inclined to play more video games, which aids in regulating emotions and reducing their intensity. Unlike the everyday environment, then, the video-game environment provides another space for emotional expression. To our knowledge, no study assessed the relation between video-game playing and emotional functioning among adolescents. However, understanding of the emotional functioning of regular players would better apprehend the transition from regular to problematic use and thus would adapt the therapeutic. For this it is essential to clarify the emotional factors involved in regular gaming before take an interest in problematic gaming.

This research explores the following hypotheses:

H1. Regular gamers tend to regulate their emotions more than other adolescents, and regular gamers have specific emotionregulation strategies.

H2. Regular gamers tend to feel their emotions with less intensity than other adolescents.

H3. Regular gamers express their emotions less than other adolescents.

H4. Regular gamers have difficulty identifying and describing emotions, which translates into a higher level of alexithymia than other adolescents.

\section{Materials and method}

\subsection{Procedure and participants}

This study is the result of my thesis work conducted from 2009 to 2012. Six schools in the city of Toulon, France, were contacted for the study. Three of the schools agreed to participate, two middle schools (6th to 9th grade) and one high school (10th to 12th grade). In each school, one class was randomly selected from each grade. After receiving information about the study, the parents were given a consent form to sign. The adolescents were also asked to give their written consent. Refusal by the parents or adolescents rarely occurred ( 6 out of 165). A total of 159 adolescents (age: M 1/4 14, SD $1 / 42$, range 10 e 18 years) took part in the study ( $52 \%$ boys). The participating adolescents filled out a questionnaire in the classroom, supervised by a researcher.

\subsection{Materials}

To identify video-game practices, the adolescents were asked to state whether they played video games on a regular basis ("Do you play video games regularly?" Yes/No). This measure allowed us to differentiate regular and irregular gamers. The adolescents were also asked to estimate the amount of time spent weekly playing video games (gaming time) during the last two months.

In order to explore some of the dimensions of adolescent video gamers' emotional functioning, we used the following tools, all validated with a population of children and adolescents.

The Emotion Regulation Questionnaire (ERQ; Gross \& John 2003) was used to assess the following emotion-regulation strategies used by adolescents: cognitive reappraisal of the situation (CR), which enables one to change the emotional character of a situation (valence and intensity), and suppression of emotion (SE), which enables one to inhibit emotion expression. This tool consists of 10 items describing different ways of feeling and expressing emotions (CR: 6 items; SE: 4 items). Subjects must assess their extent of agreement using a seven-point Likert scale (1e7; totally disagree to totally agree). In the present study, the ERQ was reliable (a $1 / 40.70)$.

The Affective Intensity Measure (AIM; Larsen \& Diener, 1987; Bryant, Yarnold, \& Grimm, 1996) was used to assess the subjects' disposition to feel emotions with a certain intensity or "characteristic strength". This "global emotion intensity" score (GEI) is based on a three-dimensional approach to emotion intensity (Bryant et al., 1996): positive affectivity (PA), which is the subject's tendency to feel positive emotions intensely; negative intensity (NI), which is the tendency to feel negative emotions intensely; and negative reactivity (NR), which is the tendency to react to negative 
emotions. This tool consists of 40 items describing emotional reactions (PA: 15 items, NI: 6 items, NR: 6 items). Subjects must state the degree to which these statements correspond to their own reactions, using a six-point Likert scale (1e6; never to always). In the present study, the AIM showed good internal consistency (a $1 / 40.85)$.

The Emotional Expressivity Scale (EES; Kring et al., 1994) was used to assess the subject's emotional expressivity. This tool consists of 17 items describing tendencies to express emotions. Subjects must state the extent to which these statements correspond to their own reactions, using a six-point Likert scale (1e6; never to always true). In the present study, the EES was reliable (a 1/4 0.90).

The Bermond-Vorst Alexithymia Questionnaire (BVAQ; Vorst \& Bermond, 2001) was used to assess the level of alexithymia (difficulty identifying and expressing one's emotions) and its five dimensions: (1) difficulty identifying the nature of one's own emotions (identifying), (2) difficulty verbalizing one's own emotional states (verbalizing), (3) difficulty being emotionally aroused by emotion-inducing events (emotionalizing), (4) difficulty analyzing one's own emotional states (analyzing), and (5) being inclined to fantasize, imagine, day-dream (fantasizing). This tool consists of 40 items (each subscale consists of 8 items), for which subjects must assess their extent of agreement using a five-point Likert scale (1e5; definitely to doesn't apply to me at all). In the present study, the BVAQ exhibited good internal consistency (a $1 / 40.75)$.

\subsection{Analyses}

We conducted descriptive and inferential analyses. The adolescents' responses to the question about their video gaming ("Do you play video games regularly?" Yes/No), divided the population into two groups: regular gamers and irregular gamers. In order to grasp video-game practices, we looked at the distribution of regular and irregular gamers by gender (chi-square analysis). We also compared regular and irregular gamers on the time spent playing video games (Mann-Whitney's U). Multivariate Analysis of Variance was performed in order to provide a combined analysis on the impact of game playing on emotional variables. Then the two groups (regular and irregular gamers) were compared on their ERQ, AIM, ES, and BVAQ scores (Student's t test). In preliminary analyzes, age categories were compared on ERQ, AIM, ES and BVAQ scores (Student's $\mathrm{t}$ test). The results showed a stability of these scores through age. Thus, we have not included age categories in our analysis.

All statistical analyses were performed using SPSS 16.0 software (SPSS Inc., Chicago, IL). A p-value less than 0.05 was considered significant.

\section{Results}

Among the 159 adolescents who participated in the study, 92 $(57.9 \%)$ were considered regular gamers (72\% boys) and 67 were considered irregular gamers ( $24 \%$ boys); $80.5 \%$ of the boys and $33 \%$ of the girls were regular gamers. The heterogeneity of this distribution was significant (Table $1, c^{2} 1 / 437.376, p<0.05$ ). There was no

\begin{tabular}{|c|c|c|c|}
\hline \multicolumn{3}{|l|}{$\begin{array}{l}\text { Table } 1 \\
\text { Video gaming and gender. }\end{array}$} & \multirow[b]{2}{*}{ Sig. } \\
\hline & Regular gamers & Irregular gamers & \\
\hline Total sample (n $1 / 4$ 159) & $92(57.9 \%)$ & $67(42.1 \%)$ & $c^{2} 1 / 437.37$ \\
\hline Boys (n $1 / 482)$ & $66(80.5 \%)$ & $16(19.5 \%)$ & $\mathrm{p}<0.05$ \\
\hline Girls (n $1 / 476)$ & $25(33 \%)$ & $51(67 \%)$ & \\
\hline
\end{tabular}

significant difference (Table 2, t $1 / 411.517, \mathrm{p}>0.05$ ) between the average age of the regular $(13.9 \pm 2.1)$ and irregular $(14.4 \pm 1.9)$ gamers. Regular gamers played significantly more than irregular gamers $\left(10.9 \pm 11.7\right.$ and $1.7 \pm 1.1$, respectively; $U^{1 / 4} 31.5$, $\left.p<0.05\right)$.

A gender effect on some cognitive-emotional variables was found (Table 3). Boys were found to suppress their emotions more than girls $(15.8 \pm 6$ and $13.7 \pm 5.5$, respectively; $\mathrm{t} 1 / 40.92, \mathrm{p}<0.05)$. Their negative reactivity was smaller than that of girls $(20.5 \pm 6.3$ and $22.9 \pm 5.7$, respectively; $t 1 / 410.72, \mathrm{p}<0.05$ ). Boys express their emotions less than did girls ( $55 \pm 16.1$ and $63.1 \pm 13.7$, respectively; $\left.\mathrm{t} 1 \frac{1}{4} 12.49, \mathrm{p}<0.01\right)$. On the measure of alexithymia, boys' alexithymia level was higher than that of girls $(108.1 \pm 18$ and $100.3 \pm 18.5$, respectively; $\mathrm{t} 1 / 413.36, \mathrm{p}<0.01$ ). And their emotional reactivity level was higher than that of girls $(22.9 \pm 5.7$ and $19.1 \pm 5.6$, respectively; $\mathrm{t} 1 / 41.19, \mathrm{p}<0.01$ ).

Multivariate Analysis of Variance (Table 4) showed the impact of game playing on emotional variables ( $F^{1 / 4} 2.108$, $p<0.05$ ), especially on emotion regulation ( $\left.\mathrm{F}^{1 / 4} 3.794, \mathrm{p}<0.05\right)$, global emotion intensity ( $F 1 / 44.713, \mathrm{p}<0.05)$, emotional expressivity $\left(\mathrm{F}^{1 / 4} 3.656\right.$, $\mathrm{p}<0.05)$ and emotionalizing $\left(\mathrm{F}^{1 / 4} 6.040, \mathrm{p}<0.05\right)$. Then, regular and irregular gamers were compared on their ERQ, AIM, ES, and BVAQ scores (Table 5). Insofar as a gender effect on some cognitiveemotional variables was found and as the regular gamers were predominantly boys $(72 \%)$, we did comparisons of means on these variables (SE, NR, EE, alexithymia and emotionalizing) by controlling the gender effect (Table 5). The regular gamers were found to regulate their emotions more than the irregular gamers did $\left(42.5 \pm 11.6\right.$ and $39 \pm 9.5$, respectively; $\left.\mathrm{t} 1 \frac{1}{4} 2.01, \mathrm{p}<0.05\right)$. By contrast, they did not differ from irregular gamers in the strategies used, and they did not suppress more emotions or do more cognitive reappraisal than did irregular gamers $(p>0.05)$. Regular games felt their emotions more intensely than irregular gamers did $(150 \pm 24.5$ and $141.3 \pm 23.9$, respectively; $\mathrm{t} 1 / 42.25, \mathrm{p}<0.05)$ However, their positive and negative affectivity and their emotional reactivity scores did not differ from those of irregular gamers ( $p>0.05$ ). Regular gamers expressed their emotions less than did irregular gamers $(56.4 \pm 15.7$ and $62.3 \pm 14.5$, respectively; $\left.t^{1 / 4} 12.41, p_{0}<0.01 ; F^{1 / 4} 6.03, h^{2} 1 / 40.07, p_{0}<0.01\right)$. Finally, on the measure of alexithymia, the regular gamers' alexithymia level was higher than that of the irregular gamers $(106.6 \pm 19$ and $101.1 \pm 17.5$, respectively; $t 1 \frac{1}{4} 1.88, \mathrm{p}>0.05 ; \mathrm{F} 1 / 43.87, \mathrm{~h}^{2} 1 / 40.05$, $\mathrm{p}<0.05)$. And their emotional reactivity level was higher than that of the irregular gamers $(22 \pm 6.2$ and $19.8 \pm 5.2$, respectively; t $\left.1 / 42.42, \mathrm{p}<0.05 ; \mathrm{F} 1 / 48.89, \mathrm{~h}^{2} 1 / 40.1, \mathrm{p}<0.01\right)$

\section{Discussion}

Regular gamers regulated their emotions more, although without favoring a particular regulation strategy (suppression of emotion or cognitive reappraisal of the situation). These results partially validated Hypothesis 1 . We can assume that because of its simplicity and consistency (Turkle, 1995), the virtual environment fosters or at least facilitates emotion regulation, no matter what strategy is used. However, our regular gamers felt their emotions more intensely than the other adolescents did. This result refuted

Table 2

Video gaming, age and gaming time.

\begin{tabular}{llccl}
\hline \hline & & Regular gamers & Irregular gamers & Sig. \\
\hline \multirow{2}{*}{ Age } & $\mathrm{M}$ & 13.9 & 14.4 & $\mathrm{t} 1 / 411.52$ \\
\multirow{3}{*}{ Gaming time } & $\mathrm{SD}$ & 2.1 & 1.9 & $\mathrm{p}>0.05$ \\
& $\mathrm{M}$ & 10.9 & 1.7 & $\mathrm{U} 1 / 431.5$ \\
& $\mathrm{SD}$ & 11.7 & 1.1 & $\mathrm{p}<0.05$ \\
\hline
\end{tabular}

M: mean, SD: standard deviation. 
Table 3

Gender and emotional functioning.

\begin{tabular}{|c|c|c|c|c|c|}
\hline & \multicolumn{2}{|l|}{ Boys } & \multicolumn{2}{|l|}{ Girls } & \multirow[t]{2}{*}{$\mathrm{t}$} \\
\hline & M & SD & M & SD & \\
\hline Emotion regulation & 42.6 & 11.6 & 39.3 & 9.9 & 1.9 \\
\hline Cognitive re-evaluation & 26.8 & 8.9 & 25.6 & 7.8 & 2.24 \\
\hline Suppression of emotion & 15.8 & 6 & 13.7 & 5.5 & $0.92^{*}$ \\
\hline Global emotion intensity & 146 & 26.2 & 148.86 & 23 & 10.55 \\
\hline Positive affectivity & 55.9 & 55.9 & 59 & 12.7 & 10.141 \\
\hline Negative affectivity & 18.1 & 5.2 & 18.7 & 4.9 & 11.51 \\
\hline Negative reactivity & 20.5 & 6.3 & 22.9 & 5.7 & $10.72^{*}$ \\
\hline Emotional expressivity & 55 & 16.1 & 63.1 & 13.7 & $12.49^{\star \star}$ \\
\hline Alexithymia & 108.1 & 18 & 100.3 & 18.5 & $13.36^{\star \star}$ \\
\hline Identifying & 20.3 & 5.7 & 20.3 & 5.7 & 2.7 \\
\hline Verbalizing & 23.7 & 6.3 & 22.6 & 5.8 & 10.05 \\
\hline Emotionalizing & 22.9 & 5.7 & 19.1 & 5.6 & $1.19^{\star \star}$ \\
\hline Analyzing & 19.3 & 7 & 17.6 & 5.3 & 4.2 \\
\hline Fantasizing & 22 & 6.2 & 20.7 & 7.7 & 1.18 \\
\hline
\end{tabular}

p $<0.05 ;{ }^{* *} \mathrm{p}<0.01$.

Table 4

Emotional functioning in video gaming.

\begin{tabular}{cll}
\hline & \multicolumn{2}{l}{$\begin{array}{l}\text { Multivariate analysis } \\
\text { of variance }\end{array}$} \\
\cline { 2 - 3 } & $\mathrm{F}$ & $\mathrm{h}^{2}$ \\
\hline Video gaming: regular gamer/irregular gamer & $2.108^{\star}$ & 0.149 \\
Emotion regulation & $3.794^{\star}$ & 0.024 \\
Cognitive re-evaluation & 1.945 & 0.012 \\
Suppression of emotion & 2.705 & 0.017 \\
Global emotion intensity & $4.713^{*}$ & 0.030 \\
Positive affectivity & 0.816 & 0.005 \\
Negative affectivity & 1.548 & 0.010 \\
Negative reactivity & 0.001 & 0.000 \\
Emotional expressivity & $5.286^{\star}$ & 0.033 \\
Alexithymia & 3.656 & 0.023 \\
Identifying & 0.104 & 0.001 \\
Verbalizing & 2.551 & 0.016 \\
Emotionalizing & $6.040^{*}$ & 0.038 \\
Analyzing & 0.012 & 0.000 \\
Fantasizing & 1.914 & 0.012 \\
\hline
\end{tabular}

${ }^{\star} \mathrm{p}<0.05 ;{ }^{\star \star} \mathrm{p}<0.01$. be linked to the regular gamers' difficulty identifying and expressing their emotions (their alexithymia level was higher than that of irregular gamers). More specifically, because the regular gamers had low emotional reactivity, they had more trouble being emotionally aroused by emotion-inducing events. In addition, they expressed their emotions less than did irregular gamers. This result validated Hypothesis 3. Classically, alexithymia is associated with a "flat emotional profile" (Zech, Luminet, Rime, \& Wagner, 1999). which results in low emotional expressiveness, low emotional intensity, and the use of few emotion-regulation strategies. But here we observed a different profile. The emotional functioning of the regular gamers highlighted by the results of this study could represent an attempt to curb the alexithymic dynamic. These results partially validated Hypothesis 4 . Within the virtual environment, adolescents may be better able to regulate the emotions they are facing. To do so, they may try to intensify their emotions in order to recognize them, respond to them, and express them. The virtual environment would act as a "virtual crutch" for staging emotional experiences, since adolescents and gamers see it as simpler, more logical, and more understandable than reality (Fortin et al., 2005; Turkle, 1995). So adolescents who fail to manage and elaborate their emotions, or who are simply unable to recognize them (alexithymia), may use the virtual environment of video games as an opportunity to experiment with and then regulate their emotions. This emotional dynamic could account for their involvement in video gaming. However, this solution may not always be very effective, or may not always be transposed onto reality. This could account for adolescents' regular or intensive involvement and the subsequent shift to addictive playing. Alexithymia would be a factor in explaining engagement in, and maintenance of, addictive behavior (Bonnet, Bejaoui, Brejard, \& Pedinielli, 2011; Brejard, Bonnet, \& Pedinielli, 2008). Moreover, addiction could perform an important emotional function for subjects. According to Peele (Peele, 1985), addiction results from an attempt to fit into one's environment and thus acts as a way of staying in control of one's emotional life. Addictive functioning, then, could be linked to risky behavior, in line with Bonnet et al. (2011) and her collaborators, by providing an adaptive solution

Table 5

Emotional variables of regular and irregular gamers.

\begin{tabular}{|c|c|c|c|c|c|c|c|}
\hline & \multicolumn{2}{|c|}{ Regular gamers } & \multicolumn{2}{|c|}{ Irregular gamers } & \multirow[t]{2}{*}{ Student's t test: $\mathrm{t}$} & \multicolumn{2}{|c|}{ Analysis of covariance: } \\
\hline & M & SD & M & SD & & $\mathrm{F}$ & $h^{2}$ \\
\hline Emotion regulation & 42.5 & 11.6 & $2.01^{\star}$ & 39 & 9.5 & & \\
\hline Cognitive re-evaluation & 27.1 & 8.9 & 1.54 & 25 & 7.5 & & \\
\hline Suppression of emotion & 15.4 & 6 & 1.52 & 14 & 5.5 & 2.6 & 0.03 \\
\hline Global emotion intensity & 150 & 24.5 & $2.25^{*}$ & 141.3 & 23.9 & & \\
\hline Positive affectivity & 58.2 & 12.3 & 0.95 & 56.2 & 14.1 & & \\
\hline Negative affectivity & 18.8 & 5.4 & 1.27 & 17.8 & 4.3 & & \\
\hline Negative reactivity & 21.8 & 6.5 & 0.17 & 21.6 & 5.7 & 2.06 & 0.01 \\
\hline Emotional expressivity & 56.4 & 15.7 & $12.41^{\star}$ & 62.3 & 14.5 & $6.03^{\star \star}$ & 0.07 \\
\hline Alexithymia & 106.6 & 19 & 1.88 & 101.1 & 17.5 & $3.87^{\star}$ & 0.05 \\
\hline Identifying & 20.4 & 5.8 & 0.26 & 20.1 & 5.6 & & \\
\hline Verbalizing & 23.8 & 6.4 & 1.57 & 22.3 & 5.5 & & \\
\hline Emotionalizing & 22 & 6.2 & $2.42^{*}$ & 19.8 & 5.2 & $8.89^{\star \star}$ & 0.1 \\
\hline Analyzing & 19.1 & 6.5 & 0.1 & 17.6 & 6 & & \\
\hline Fantasizing & 21.4 & 6.7 & 1.42 & 21.3 & 7.4 & & \\
\hline
\end{tabular}

${ }^{\star} \mathrm{p}<0.05 ;{ }^{\star *} \mathrm{p}<0.01$.

Hypothesis 2. Emotion regulation consists of modifying the quality and intensity of the concerned emotion in order to be able to manage it and make it psychologically meaningful. Emotion regulation by regular gamers seems to consist of increasing the emotion's intensity. The "intensification" of emotional experience may for controlling and regulating problematic emotional experiences.

The majority of regular players are boys (Fortin et al., 2005; Griffiths \& Hunt, 1995). Although gender parity presently exists in terms of the number of users, a difference persists in how video games are used. Boys exhibit more regular or intensive gaming 
while girls play more occasionally (Cruea \& Parks, 2012; Fox \& Tang, 2014; Homer, Hayward, Frye, \& Plass, 2012). Video-game playing is predominantly done by male adolescents (Bioulac \& Michel, 2012) and is generally regarded as a male activity by the players themselves (Fox \& Tang, 2014). Different approaches have attempted to provide explanations of this disparity in terms of attractiveness of competition (Olson, 2010), content, and social issues related to video games (Burgess, Stermer, \& Burgess, 2007; Fox \& Tang, 2014; Salter \& Blodgett, 2012; Williams, Martin, Consalvo \& Ivory, 2009). Mediation of emotional experiences by video games could also account for the disparity. Adolescents are emotionally motivated to play (Olson, 2010), and video-game playing may not only relieve stress and anger, but also provide positive emotions (Olson, 2010). In general, boys tend to regulate their emotions less, feel them with less intensity, and express them less often (Bryant et al., 1996; Christophe, Antoine, Leroy, \& Delelis, 2009; Kring et al., 1994). However, our results showed that emotional functioning was reversed with regular gamers as compared to irregular gamers (the former regulated their emotions more and experienced them with greater intensity). Such differences in gaming time may stem from players' emotional experiences with the games themselves (Homer et al., 2012).

Finally, it is important to question our division into regular and irregular gamers. We used the subjective position of the subject. Although criticizable, this criterion seems like a good one for grasping the subjects' involvement in, and representations of, their own video-game playing (Elliott, Golub, Ream, \& Dunlap, 2012). Even though this is a subjective position, our data on the time spent playing video games seems to confirm this positioning. However, having only one question as the criterion seems to lack discriminative sensitivity since the class of regular gamers can be vast. In this vein, Virole (2012) distinguished six levels of video-game practice, from regular daily playing to pathological playing, in which "regular video gaming" encompasses different ways of using video games and different degrees of utility. It would therefore be interesting to look at the different levels of video gaming in future research in order to analyze the emotional functioning associated with each one. Moreover, in order to continue this work, we consider it essential to focus on the virtual experience felt by players. Indeed, the current gaming time is not a sufficient indicator to understand the whole dynamic. It seems important to know how long a specific gaming time is installed in order to differentiate the players and so to go further in understanding the dynamics.

To conclude, we are witnessing a growing theoretical and empirical interest in video gaming, particularly among adolescents. In health centers for adolescents, questions are arising concerning how to organize care and support for gamers whose use of video games is excessive or problematic. To do so, it is necessary to first understand video gaming and its implications for the gamer. The emotional self characterizes and organizes emotional experience (Lupton, 1998). It allows one to integrate external elements, adapt to them, and relate to the surrounding world (Lupton, 1998). The challenge of adolescence, in conjunction with identity construction, would involve being able to manage one's emotions, and thus one's relationship to the world. The virtual environment may help achieve this goal. Indeed, the avatar's evolution in the virtual environment would mediate problematic emotional experiences, make them meaningful, and enable their appropriation. In adolescence, many intense emotions that are difficult to understand emerge, and for some, this intense emotional experience becomes problematic. The adolescent fails to identify and describe his/her emotions, and is unable to regulate them, express them, or appease them. In this case, video-game playing could provide a support, a scene for projecting and experiencing one's emotional life. In sum, the staging of the emotional self (Lupton, 1998) would underlie adolescents' engagement in the practice of video gaming.

Author disclosure statement

No competing financial interest exists.

\section{References}

Bessiere, K., Seay, F., \& Kisler, S. (2007). The ideal elf: identity exploration in world of warcraft. Cyber Psychology and Behavior, 10(4), 530e535.

Bioulac, S., \& Michel, G. (2012). Addiction: definition et psychopathologie [Addiction: definition and psychopathology]. In L. Romo, S. Bioulac, L. Kern, \& G. Michel (Eds.), La dependance aux jeux video et a Internet (pp. 15e30). Paris: Dunod.

Blaszczynski, A. (2008). Commentary: a response to "Problems with the concept of video game "addiction": some case study examples". International Journal of Mentam Health and Addiction, 6, 179e181.

Bonnet, A., Bejaoui, M., Brejard, V., \& Pedinielli, J. L. (2011). Dependance physiologique et fonctionnement emotionnel chez les jeunes adultes: affectivite, intensite emotionnelle et alexithymie dans la consommation de substances psychoactives [Physiological dependence and emotional functioning among young adults: affectivity, emotional intensity and alexithymia in the use of psychoactive substances]. Annales Medico Psychologiques, 169, 92e97.

Brejard, V., Bonnet, A., \& Pedinielli, J. L. (2008). Regulation des emotions, depression et conduites a risques: l'alexithymie un facteur moderateur [Emotion regulation, depression and risk behaviors: alexithymia a moderating factor]. Annales Medico Psychologiques, 166, $260 e 268$.

Bryant, F. B., Yarnold, P. R., \& Grimm, L. G. (1996). Toward a measurement model of affect intensity measure: a three-factor structure. Journal of Research in Personality, 30, $223 \mathrm{e} 247$.

Burgess, M. C., Stermer, S. P., \& Burgess, S. R. (2007). Sex, lies, and video games: the portrayal of male and female characters on video game covers. Sex Roles, 57 , 419 e 433.

Christophe, V., Antoine, P., Leroy, T., \& Delelis, G. (2009). Evaluation de deux strategies de regulation emotionnelle: la suppression expressive et la reevaluation cognitive [Evaluation of two strategies of emotional regulation: expressive suppression and cognitive reappraisal]. Revue Europeenne de Psychologie Appliquee, 59, 59e67.

Craipeau, S., \& Seys, B. (2005). Jeux et internet: quelques enjeux psychologiques et sociaux [Games and internet: some psychological and social issues]. Psychotropes, 11(2), $101 \mathrm{e} 127$

Cruea, M., \& Parks, S. (2012). Gender disparity in video game usage: a third person perception-based explanation. Media Psychology, 15, 44e67.

Dorard, G., Berthoz, S., Phan, O., Corcos, M., \& Bungener, C. (2008). Affect dysregulation in cannabis abusers: a study in adolescents and young adults. European Child and Adolescent Psychiatry, 17, 274e282.

Elliott, L., Golub, A., Ream, G., \& Dunlap, E. (2012). Videogame genre as a predictor of problem use. Cyber Psychology, Behavior \& Social Networking, 15(3), 155e161.

Fortin, T., Mora, P., \& Tremel, L. (2005). Les jeux video: pratiques, contenus et enjeux sociaux [Video games: practices, contents and social issues]. Paris: L'Harmattan.

Fox, J., \& Tang, W. Y. (2014). Sexism in online video games: the role of conformity to masculine norms and social dominance orientation. Computers in Human Behavior, 33, 314e320.

French Videogame Agency. (2010). Mediametrie: Observatoire des jeux video [Mediametrie: video games' observatory]. From http://www.afjv.com/ press 1007/100708_observatoire_jeux_video_joueuses.php.

Gaetan, S., Bonnet, A., \& Pedinielli, J. L. (2012). Perception de soi et satisfaction de vie dans l'addiction aux jeux video chez les jeunes adolescents (11e14 ans) [Self-perception and satisfaction with life in addiction to video games among young adolescents (11e14 years)]. L'Encephale, 38, 512e518.

Gentile, D. A. (2009). Pathological video-game use among youth ages 8e18. Psychological Science, 20, 594e602.

Greenberg, L. (2004). Emotion-focused therapy. Clinical Psychology and Psychotherapy, 11, 3e16.

Greenwood, D. N. (2008). Television as escape from self: psychological predictors of media involvement. Personality and Individual Differences, 44, 414e424.

Greenwood, D. N., \& Christopher, R. L. (2009). Mood specific media use and emotion regulation: patterns and individual differences. Personality and Individual differences, 46, 616e 621

Griffiths, M. D. (2010). Online video gaming: what should educational psychologist know? Educational Psychology in Practice, 26(1), 35e40.

Griffiths, M. D., Davies, M. N., \& Chappell, D. (2004). Demographic factors and playing variables in online computer gaming. Cyber Psycholgy \& Behavior, 7, 479 e 487.

Griffiths, M. D., \& Hunt, N. (1995). Computer games playing in adolescence: prevalence and demographic indicators. Journal of Community and Applied Social Psychology, 5, 189e193.

Gross, J. J., \& John, O. P. (2003). Individual differences in two emotion regulation processes: implications for affects, relationships and well-being. Journal of Personality and Social Psychology, 85, 348e362.

Homer, B. D., Hayward, E. O., Frye, J., \& Plass, J. L. (2012). Gender and player characteristics in video game play of preadolescents. Computers in Human Behavior, 
28,1782 e1789.

Interactive Software Federation of Europe. (2010). Video gamers in Europe 2010 From http://www.isfe.eu/sites/isfe.eu/files/video_gamers_in_europe_2010.pdf.

Janssen, C., \& Tortolano, S. (2010). Mondes virtuels et capacite d'illusion: les avatar du lien [Virtual worlds and illusion capacity: the avatars of the link]. Cahiers de psychologie clinique, 35(2), 57e76.

Ko, C., Yen, J., Chen, C., Yeh, Y., \& Yen, C. (2009). Predictive values of psychiatric symptoms for internet addiction in adolescents: a 2 -year prospective study. Archives of Pediatrics and Adolescent Medicine, 163, 937e943.

Kring, A. M., Smith, D. A., \& Neale, J. M. (1994). Individual differences in the dispositional expressiveness: development and validation of the emotional expressivity scale. Journal of Personality and Social Psychology, 66, 964e949.

Larsen, J., \& Diener, E. (1987). Affect intensity an individual differences characteristic: a review. Journal of Research in Personality, 21, 1 e39.

Lupton, D. (1998). The emotional self. A sociocultural exploration. London: Sage Publications.

Lyon, M., \& Bardalet, J. (1994). Society's body: emotion and the "somatization" of social theory. In T. Csordas (Ed.), Embodiment and experience: the existentia ground of culture and self (pp. 48e66). Cambridge: Cambridge University Press.

Michel, G. (2001). Recherche de sensations et conduites a risque chez l'adolescen [Sensations seeking and risk behavior among adolescents]. Annales Medico Psychologiques, 159, 708 e 716.

Mullin, B. C., \& Hinshaw, S. P. (2007). Emotion regulation and externalizing disorders in children and adolescents. In G. J. Dans (Ed.), Handbook of emotional regulation (pp. 523e541). New York: Guilford Press.

Olson, C. K. (2010). Children's motivations for video game play in the context of normal development. Review of General Psychology, 14(2), 180e187.

Peele, S. (1985). The meaning of addiction. Compulsive experience and its interpretation. Massachsetts/Toronto: Lexington Books.

Salter, A., \& Blodgett, B. (2012). Hypermasculinity and dickwolves: the contentious role of women in the new gaming public. Journal of Broadcasting \& Electronic Media, 56, 401e416.

Seung-A, A. (2011). "My avatar behaves well and this feels right": ideal and ought selves in video gaming. Social Behaviour and Personality, 39(9), $1175 e 1182$.
Southam-Gerow, M. A., \& Kendall, P. C. (2002). Emotion regulation and understanding. Implications for child psychopathology and therapy. Clinical Psychology Review, 22, 189e222.

Turkle, S. (1995). Life on the screen: Identity in the age of the internet. New York: Simon \& Schuster.

Turner, N. (2008). A comment on "problems with the concept of video game "addiction": some case study examples". International Journal of Mental Health and Addiction, 6, 186e190.

Virole, B. (2012). La complexite de Soi [The complexity of the Self]. Orsay France: Charielleditions.

Vorst, H. C., \& Bermond, B. (2001). Validity and reliability of the Bermond-Vorst alexithymia questionnaire. Personality and Individual Differences, 30, 413e434.

Wan, C. S. \& Chiou, W. B. (2006). Why are adolescents addicted ton online gaming? An interview study in Taiwan. Cyber Psychology and Behavior, 9(6), 649e652.

Weissberg, J. L. (2006). Presences a distance. Deplacement virtuel et reseaux numeriques [Presences at a distance. Virtual displacement and digital networks] Paris: L'Harmattan.

Williams, D., Martins, N., Consalvo, M., \& Ivory, J. D. (2009). The virtual census: representations of gender, race and age in video games. New Media \& Society, 11 $815 e 834$.

Wood, R. (2008). Problems with the concept of video game "addiction": some case study examples. International Journal of Mental Health Addiction, 6, 169 e178.

Yen, J., Yen, C. Chen, C., Chen, S. \& Ko, C. (2007). Family factors of internet addiction and substance use experience in Taiwanese adolescents. Cyber Psychology \& Behavior, 10, 323e329.

Young, K. (2009). Understanding online gaming addiction and treatment issues for adolescents. The American Journal of Family Therapy, 37, $355 e 372$.

Zech, E., Luminet, O., Rime, B., \& Wagner, H. L. (1999). Alexithymia and its measurement. Confirmatory factor analyses of the twenty-item Toronto alexithymia scale and the Bermond-Vorst alexithymia questionnaire. European Journal o Personality, 13, 511 e532.

Zimmermann, G. (2006). Delinquency in male adolescents: the role of alexithymia and family structure. Journal of Adolescence, 29(3), 321 e332. 